\title{
Size resolved dust emission fluxes measured in Niger during 3 dust storms of the AMMA experiment
}

\author{
M. Sow ${ }^{1,3}$, S. C. Alfaro ${ }^{1}$, J. L. Rajot $^{3}$, and B. Marticorena ${ }^{2}$ \\ ${ }^{1}$ Laboratoire Interuniversitaire des Systèmes Atmosphériques (LISA), UMR CNRS/INSU 7583, IPSL, Université de Paris \\ 12-Val de Marne, Créteil, France \\ ${ }^{2}$ Laboratoire Interuniversitaire des Systèmes Atmosphériques (LISA), UMR CNRS/INSU 7583, IPSL, Université de Paris \\ 7-Denis Diderot, Paris, France \\ ${ }^{3}$ Institut de Recherche pour le Développement (IRD), UMR IRD 211 Bioemco, Niamey, Niger
}

Received: 9 January 2009 - Published in Atmos. Chem. Phys. Discuss.: 2 March 2009

Revised: 17 May 2009 - Accepted: 2 June 2009 - Published: 15 June 2009

\begin{abstract}
During the 2006 and 2007 special observing periods of the African Monsoon Multidisciplinary Analysis campaign an original experimental system has been implemented in Banizoumbou (Niger) for measuring the size-resolved dust emission flux in natural conditions and documenting the possible influence of wind speed on its size distribution. The instrumental set-up, associated methodology, and the quality tests applied to the data set are described before the results acquired during 2 events of the Monsoon type and 1 of the convective type are analyzed in detail. In good agreement with the theory of sandblasting, it is found in all cases that saltation must take place for a vertical emission flux to be detected. During a particular erosion event, the magnitude of the vertical flux is controlled by the surface roughness, which conditions the saltation threshold, and by the wind friction velocity. The dust flux released by the high energy convective event is also found to be much richer in very fine $(<2 \mu \mathrm{m})$ particles than those of the relatively moderate Monsoon event, which shows that aerodynamic conditions definitely influence the initial size distribution of the erosion flux as previously suggested by wind tunnel experiments. However, the size distribution of the dust released by a given event is fairly constant and insensitive to even relatively important variations of $u^{*}$. This is interpreted as a possible result of the rather long duration $(15 \mathrm{~min})$ over which wind fluctuations must be averaged for computing $u^{*}$, which could make it an inadequate parameter for representing the very short response-time physical processes that are at the origin of fine dust emission at the measurement sites.
\end{abstract}

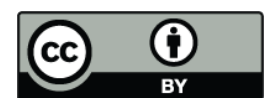

Correspondence to: $\mathrm{M}$. Sow (sowmomo2003@yahoo.fr)

\section{Introduction}

Huge amounts of mineral particles are released by wind erosion in arid and semi arid areas. Although some 'giant' desert particles with diameters as large as $100 \mu \mathrm{m}$ have been observed occasionally at remote ocean locations (e.g. Jaenicke et al., 1971), it is usually considered that only the finest dust particles - those with sizes smaller than $20 \mu \mathrm{m}$ and hereinafter referred to as FD - can remain suspended in the troposphere for several days and be transported very far from their source. During this suspension phase they interact with solar and terrestrial radiation therefore having a direct impact on climate. They may alter it also indirectly by favoring cloud formation (Levin et al., 1995). In semi-arid areas that are already poor in soil-nutrients the loss of fine dust that is naturally enriched in them (Bielders et al., 2002) can promote desertification. At the other end of the dust cycle, input of mineral particles in deposition areas can enhance the development of terrestrial or marine ecosystems (Swap, 1992; Jickells et al., 2005). Because it conditions at the same time the potential of air suspended particles for long range transport and the way these particles interact with solar and terrestrial radiation, the initial size distribution of dust emitted in source areas is a crucial parameter for the quantification of its impacts. Unfortunately, the size distribution of emission fluxes has seldom been measured in natural source areas and, for lack of sufficient field data, it has often been assumed in the past to be independent of meteorological conditions prevailing during emission. In particular, wind speed was usually considered to drive the magnitude of the emission flux but not to have any effect on the initial size distribution. This simplification allowed the use of fixed "standard" size-distribution - the most frequently used being the one

Published by Copernicus Publications on behalf of the European Geosciences Union. 
proposed by d'Almeida and Schütz (1983) - for representing the initial state of dust in source areas. However, more recent measurements performed in a laboratory wind tunnel have questioned this independence (Alfaro et al., 1997, 1998). Indeed, these measurements showed that, along with some of the soil characteristics (in particular the size of the wind erodible sand grains present at the soil surface), wind speed had a significant influence on the original size distribution of the dust flux. The model derived from these observations (Alfaro and Gomes, 2001) has been validated indirectly by comparing the total dust flux measured on the field with the one obtained by summing the masses predicted in each size class (Gomes et al., 2003; Rajot et al., 2003; Alfaro et al., 2004) but comparing the laboratory findings with size-resolved measurements performed in natural source areas is essential to increase the accuracy of models describing the dust cycle and its impacts. An original experiment was performed in the frame of the African Monsoon Multidisciplinary Analysis (AMMA) program over an agricultural field in Banizoumbou (Niger). Measurements made during the 2006 and 2007 wind erosion periods were aiming at documenting directly, and for the first time, the original size distribution of fine dust emission flux in a variety of wind conditions.

Thus, the main objective of this work is to analyze the influence of wind speed on the size distribution of the fine dust (FD) emission flux during some of the major dust emission events that occurred during the two AMMA observations periods. After summarizing briefly the current understanding of the two wind erosion processes that lead to emission of fine dust particles by arid and semi-arid soils the first section of this paper describes the original experimental set-up implemented at the Banizoumbou AMMA supersite during the dust emission season. This set-up was designed specially to document in real time all the factors that control the fine dust flux and its size distribution. The second section analyses in detail the characteristics of three major dust events monitored during the 2006 and 2007 observation periods. Special attention is paid to the influence of wind speed on the size distribution of the fine particle flux. Finally, the last section draws the conclusions of the study.

\section{Methods and material}

\subsection{Aeolian processes involved in dust emission}

The mass of FD present in a free state at the surface of wind erodible soils is usually insignificant (Chatenet et al., 1996). These particles, which do exist within the soil, are generally incorporated into coarser, sand-sized, aggregates. The setting into motion of these coarse particles (saltation process) by wind stress is a threshold effect and all the equations that have been proposed (see Greeley and Iversen., 1985, for a review) to quantify their movement involve the threshold fric- tion velocity $u^{*}{ }_{t}$ under which wind stress is too low to counterbalance weight and inter-particle forces that tend to maintain aggregates on the ground. The value of $u^{*}{ }_{t}$ not only depends on the free particles' size $(D)$ and density $(\rho)$ but also on the degree of protection brought to them by non-erodible elements (pebbles, boulders, clods, ridges, vegetation, etc). Because these elements increase at the same time $u^{*}{ }_{t}$ and the soil roughness length $\left(Z_{0}\right)$, Alfaro and Gomes (1995) and Marticorena and Bergametti (1995) have been able to model their influence on $u^{*}{ }_{t}$ by using $Z_{0}$ as a proxy. Finally, soil surface humidity can also hinder saltation by promoting the development of capillary forces between grains (Fécan et al., 1999). In the same way, physical (Gomes et al., 2003) and biological (see Belnap, 2003, for a review) crusts can reduce saltation dramatically by binding particles which were previously free to move on the soil surface.

It is when saltating sand-sized aggregates hit the ground at the downwind end of their trajectories that a fraction of their kinetic energy can be used to eject finer dust particles either from the aggregates themselves or from the soil surface on which they impact (sandblasting process). There is much experimental evidence (e.g. Gillette, 1977; Shao et al., 1993; Houser and Nickling, 2001) that direct mobilization by aerodynamic forces plays a minimal role in FD emissions, and that dust emission generally does not occur in the absence of saltation. Wind tunnel studies (Alfaro et al., 1997, 1998) also show that the larger the kinetic energy of the saltating grains, the larger the proportion of very fine particles in the emission flux, which in turn explains the influence of wind speed on the size distribution of this flux.

\subsection{Measurements}

It results from the theoretical considerations developed above that meteorological parameters and characteristics of both the saltation and vertical emission fluxes must be monitored simultaneously and in quasi real time in order to understand fully the emission of dust from a given source. This has been done at the Banizoumbou supersite during the two AMMA special observation periods (SOP) of 2006 and 2007, which were chosen to coincide with the time of year when the probability of observing dust emission is highest (Bielders et al., 2004). The following paragraphs describe the site location and the experimental set-up implemented on it.

\subsubsection{Site location and instrumentation linked to clima- tology of erosive events}

The AMMA super site of Banizoumbou $\left(13.5^{\circ} \mathrm{N} 2.6^{\circ} \mathrm{E}\right)$, is located in a remote location about $60 \mathrm{~km}$ east of Niamey, the capital of Niger. This site has been operational since the early nineties, when the first measurements of soil erosion were performed in parallel on a cultivated field and a fallow (Rajot et al., 1995; Rajot, 2001). Three years of continuous measurements showed that the main wind erosion events 
occur at the onset and beginning of the rainy season from May to mid-July, when the protection of soil surface by crop residue is the lowest and wind intensity the highest (Bielders et al., 2004). This period corresponds to the beginning of Monsoon period and differs from the dry season by a dramatic change of meteorological parameters due to the shift of the ITCZ (Inter-Tropical Convergence Zone) toward the North. Wind blows from South West bringing humidity from Atlantic Ocean to the continental atmosphere. When water vapour content is large enough in the Monsoon layer convective systems of different dimensions can form. Local events cover a few tens of square kilometres only but huge well organized systems (Mesoscale Convective System - MCS), known as squall lines, sweep out the Sahel from east to west (i.e. in direction opposite to the Monsoon flux). Whatever their scale, convective systems produce strong erosive wind, generally followed by rainfall. If the direction of squall lines is usually centred around $90^{\circ} \mathrm{N}$, smaller local systems can be associated with much more variable directions. For instance, Bielders et al. (2000) found that $85 \%$ of the 67 storms monitored in a period of 3 years had come from the northeast to south $\left(45-180^{\circ}\right)$ sector. Our own measurements (see below) show that less intense saltation events can also be observed between $150^{\circ}$ and $270^{\circ}$, which is to say in the typical direction of the Monsoon flux.

With a cultivated surface of more than 20 ha in 2006 and 2007, the agricultural field on which the experiment was set up was one of the largest in the area. The measurement devices were installed near the centre of the field in order to ensure a maximal fetch in the directions associated with wind erosion. This fetch varied between $190 \mathrm{~m}$ in the northeast direction and $575 \mathrm{~m}$ in the south direction (see Fig. 2 in Rajot et al., 2008).

The measurement station consisted in a container buried underground and a tower, both of which were equipped with a unique wind-oriented multi-line sampling inlet described in Rajot et al. (2008). The sampling system was designed specially to allow collection of large sized particles and its estimated cut-off diameter is around $40 \mu \mathrm{m}$. The inlet openings were located at 2.1 and $6.5 \mathrm{~m}$ above the soil surface for the container and the tower, respectively. The various instruments connected to each inlet were taking a fraction of the main air flow collected by the heads. The container was implemented underground in order to avoid disturbances in the airflow for the lowest measurement height, and the tower designed to protect instruments from dust and sand laden wind and from rainfall was located $3.8 \mathrm{~m}$ north of the container (Fig. 1). This position was chosen because the probability of observing an erosive event coming from the north, and during which the tower would shadow the container, was very small. For the same reason and also to avoid contamination of the measurements, the $10 \mathrm{kVA}$ diesel power generator providing electricity to the container and the tower was installed $160 \mathrm{~m}$ north of the instruments.

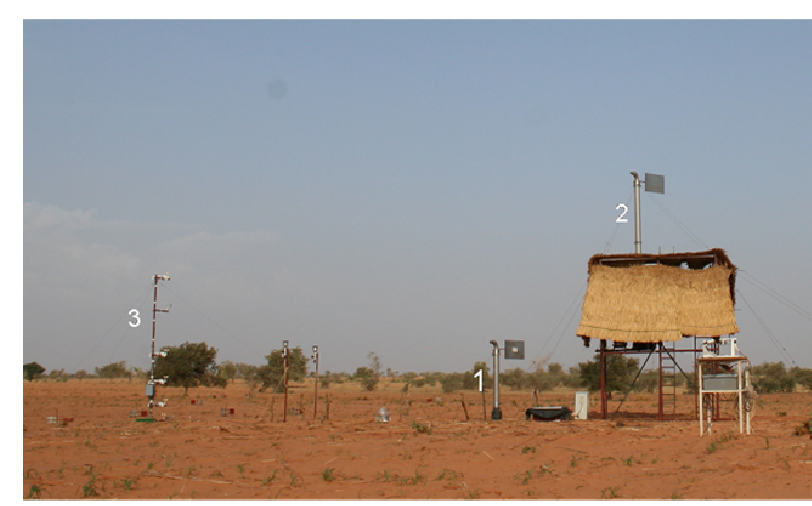

Fig. 1. View of the experimental site showing the two sampling systems located at elevations of $2.1 \mathrm{~m}$ above the buried container (1) and of $6.5 \mathrm{~m}$ on the tower (2), and the meteorological mast (3).

\subsubsection{Details of the experimental set-up and associated methodologies}

\section{Local meteorological parameters}

A meteorological mast was equipped with a wind vane (W200P Vector Instrument ${ }^{\circledR}$ ) for monitoring wind direction, 5 anemometers (A100R Vector Instrument ${ }^{\circledR}$ ), and 4 temperature probes (ASPTC, Aspirated Shield with Fine Wire Thermocouple type Chromel Constantan; Campbell ${ }^{\circledR}$ ) positioned above ground level at $0.35,0.8,1.5,2.32,4.75$ and 0.59 , $1.27,2.11$, and $4.48 \mathrm{~m}$, respectively. They provide the wind and temperature profiles necessary for the computation of the wind friction velocity and soil roughness length involved in the Monin-Obukhov similarity theory (Monin and Obukhov, 1954).

$U(z)=\frac{u^{*}}{k}\left[\ln \left(\frac{z}{z_{0}}\right)-\psi_{m}\left(\frac{z}{L}\right)+\psi_{m}\left(\frac{z_{0}}{L}\right)\right]$

In this equation, $U(z)$ is the average horizontal component of wind speed measured at height $z, k$ is von Karman's constant (0.4), $L$ is Monin-Obukhov's length reflecting the thermal stability of the surface boundary layer (SBL), and $\Psi_{m}$ is the momentum stability function. Note that though the wind speed was measured every $10 \mathrm{~s}$ and averaged over periods of $1 \mathrm{~min}$, the computation of $u^{*}$ is usually performed over durations of $15 \mathrm{~min}$, at least, because this minimal duration is necessary for integrating the major time scales of turbulence occurring in the atmosphere surface boundary layer (Wieringa, 1993). This implies that the methods based on the use of $u^{*}$, and in particular the gradient method described below, cannot be applied if the duration of the dust emission is less than $15 \mathrm{~min}$. This constitutes a strong limitation in the use of our dataset because many of the dust events observed during the two SOP lasted less than this minimal duration. It was in particular the case of convective systems, which raised huge amounts of dust but were usually short-lived. 
Practically, $u^{*}, Z_{0}$, and L-values were obtained by using the iterative routine optimized by Frangi and Richard (2000) for fitting the wind speed and temperature measurements to Eq. (1). This procedure was applied only to wind speeds larger than $1 \mathrm{~m} / \mathrm{s}$. Furthermore, the quality of the inversion procedure was considered acceptable only if the difference between the computed and measured profiles was less than $5 \%$ for wind speeds and less than $0.05 \mathrm{~K}$ for temperatures (Marticorena et al., 2006).

\section{Time occurrence of local erosion events}

For identifying the exact time location and assessing the duration and intensity of the local erosion events two different sensors were used on the field: one Saltiphone (Eijkelkamp, Giesbeek, The Netherlands, Spaan and van den Abeele, 1991) in 2006 and a Sensit (model H11B, http: //www.sensit.com/ in 2007. The physical principle on which both instruments are based is the same. They are built around a detection device (a microphone and piezoelectric quartz for the Saltiphone and Sensit, respectively) whose surface is sensitive to the impacts of saltating sand grains. The Saltiphone is rotating to face the wind while the piezoelectric quartz has a $360^{\circ}$ field of view. These detectors were positioned directly inside the saltation layer at an elevation above the soil surface of $7 \mathrm{~cm}$, approximately. Even though the two saltation detectors were not calibrated and consequently do not provide the value of the vertically integrated horizontal flux $\left(\mathrm{F}_{h}\right)$, the number of impacts they counted per time unit $(10 \mathrm{~s}$, in our experiments) is a means of assessing precisely the time occurrence of saltation and provides an indication of its intensity. Regarding this last point, note that the responses of the two detectors cannot be compared directly because the sensitivities of the two instruments were certainly different. In addition, their elevation inside the saltation layer was not exactly the same, which has a direct influence on the number of grains hitting the detectors. Indeed, the larger the elevation, the lower the number of impacts for a given saltation intensity.

\section{Computation of the FD emission flux by the gradient method}

Assuming that the particles with aerodynamic diameters smaller than $20 \mu \mathrm{m}$ were light enough to follow air movements perfectly, Gillette (1972) proposed an equation based on the similarity of air momentum and particle mass exchanges in the SBL for expressing the upward vertical mass flux of such particles.

$$
F_{v}=u^{*} k \frac{\left(C_{l}-C_{h}\right)}{\ln \left(\frac{z_{h}}{z_{l}}\right)-\psi_{m}\left(\frac{z_{h}}{L}\right)+\psi_{m}\left(\frac{z_{l}}{L}\right)}
$$

This equation can be used to derive the vertical mass flux of particles from mass concentrations measured directly at the heights $\left(z_{h}\right.$ and $\left.z_{l}\right)$ of the two sampling heads by two TEOM microbalances (TEOM, model 1400a, Rupprecht and Patashnick Albany, New York USA) connected to them. It can also be adapted to yield the vertical fluxes $\left(\mathrm{F}_{v, i}\right)$ of particles belonging to different size classes (each of which is denoted by a different value of the subscript i):

$$
F_{v, i}=u^{*} k \frac{\left(C_{l, i}-C_{h, i}\right)}{\ln \left(\frac{z_{h}}{z_{l}}\right)-\psi_{m}\left(\frac{z_{h}}{L}\right)+\psi_{m}\left(\frac{z_{l}}{L}\right)}
$$

In this work the $C_{l, i}$ and $C_{h, i}$ appearing in Eq. (2b) are the number concentrations measured every minute in the ith class of two identical optical particle sizers (GRIMM OPC 1.108, GRIMM Aerosol Technik GmbH \& Co., Ainring, Germany) also connected to the low and high sampling heads. These size distribution measurements were performed with maximal care. Prior to the experiment itself, the two counters were cross-calibrated channel by channel by using them to measure at the same heights and for a duration of 20 days the size-resolved concentration of ambient particles. In all channels except the coarsest one, an excellent correlation was found ( $R=0.93$ for the coarsest channel and $R>0.98$ for all the others). The slopes of the regressions comprised between 0.87 and 1.13 , depending on the channel, were subsequently used to correct the concentrations used for the flux computation. Note that as detailed in Rajot et al. (2008), the sampling heads had also been designed to avoid any size distribution bias due to particle collection and carefully intercompared. The OPS sort particles in 15 size-classes ranging from 0.3 to $20 \mu \mathrm{m}(0.3-0.4,0.4-0.5,0.5-0.65,0.65-0.80$, $0.8-1.0,1.0-1.6,1.6-2.0,2.0-3.0,3.0-4.0,4.0-5.0,5.0-$ $7.5,7.5-10,10-15,15-20,>20 \mu \mathrm{m})$. It must also be mentioned that a systematic underestimation of the particle concentration is always observed in the $1.0-1.6 \mu \mathrm{m}$ size class. This problem seems to be inherent to the Grimm OPS instrument and was also visible on the comparison of its measurements with those of an aerodynamic particle sizer (TSI, model 3321) used in parallel to size a unique aerosol (Peters et al., 2006). Naturally, this bias leads to an underestimation of the emission flux in the $1.0-1.6 \mu \mathrm{m}$ class, which is accounted for in this work by interpolating the results obtained in the two surrounding size classes $(0.8-1.0 \mu \mathrm{m}$ and 1.6-2.0 $\mu \mathrm{m})$. Lastly, the saturation of the finest counter channels that was observed during the strongest events of 2006 lead us to implement air diluters (TOPAS, model 1400a, $R$ ) of 0.01 dilution factors on the OPS for the 2007 experiment.

The TEOM mass measurements performed in exact parallel with the size-resolved number concentrations are not only used in this work to compute the vertical mass flux according to Eq. (2a) but also to test the consistency of the independent mass and number measurements. More precisely, the total mass concentration measured by the TEOM is plotted against the accumulated particle volume reconstructed using the measurements in each size class of the OPS and assuming particle sphericity. This procedure yields an equivalent mass density of dust particles for each event and for the two 


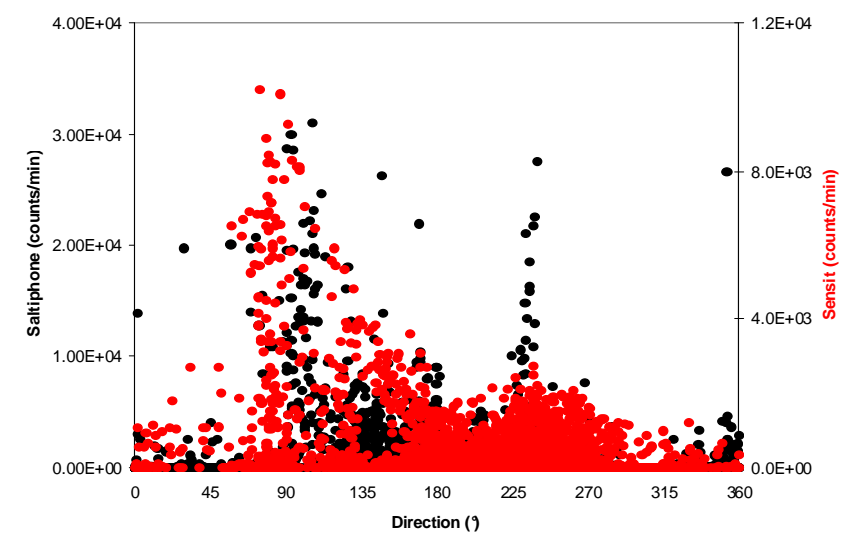

Fig. 2. Wind directions associated with the erosion events detected by the two sand movement detectors (Saltiphone and Sensit) operated successively during the 2006 and 2007 AMMA field campaigns. Numerical counts correspond to the number of shocks monitored each minute by the sensing part of the instruments.

sampling levels. Practically, the measurements performed during an event will be considered as valid if no discrepancy indicative of a measuring problem is observed between the two values.

In summary, Eq. (2) and the parallel measurements of both the meteorological parameters and particle size resolved concentrations at two different heights in the SBL provide a way of assessing the size-resolved emission fluxes in the OPS measurement range. Practically, concentrations measured every minute were averaged over durations of $15 \mathrm{~min}$ in order to remain in keeping with the $u^{*}$ computation. Note that the fine time resolution of the vertical fluxes computed with these values is a substantial improvement over the traditional gradient method that was based on the weighing of particles collected on filters for much longer durations.

\section{Results and comments}

\subsection{Typology of wind erosion events and result of data selection:}

During the two SOPs, numerous saltation events were detected by either the Saltiphone (2006) or the Sensit (2007). The majority of these events are caused by winds blowing from directions located between $45^{\circ}$ and $270^{\circ}$ (Fig. 2), that is to say approximately from the east to southwest sector. Figure 2 shows that the more intense saltation activity is recorded between $45^{\circ} \mathrm{N}$ to $180^{\circ} \mathrm{N}$, which is perfectly in agreement with results of Bielders et al. (2000). Nevertheless, less intense but more frequent saltation also occurred between 150 and $270^{\circ}$. Direct field visual observations confirm this sorting of events into two main categories: events that are simply due to a temporary increase in the speed of the southwestern monsoon wind, mainly between 150 and

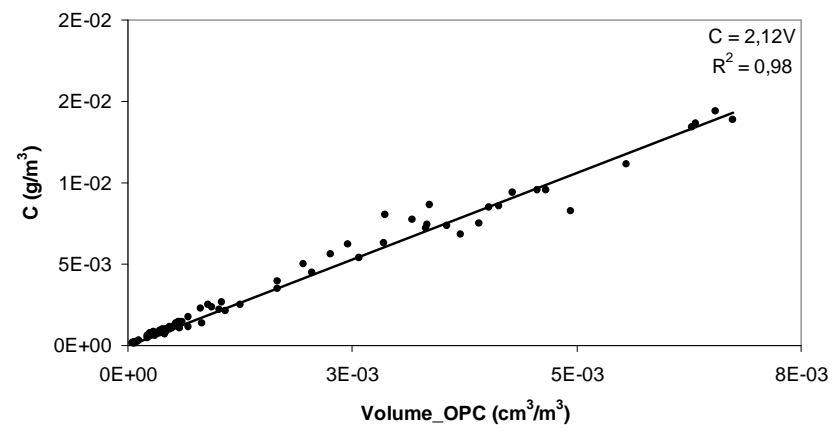

Fig. 3. Illustration of the good consistency $\left(r^{2}=0.98\right)$ between the mass concentration $(\mathrm{C})$ recorded directly with a TEOM microbalance and the volume concentration reconstructed from the sizeresolved number concentration measurements made with an optical particle counter. The data used in this figure are those acquired at the lowest measurements level during ME1. The slope of the straight line (2.12) is the particle's equivalent mass density.

$270^{\circ}$ (monsoon events or ME) and events associated with the passage of convective systems, mainly between 45 and $180^{\circ}$ (convective events or CE). Though not systematically, the latter are often followed by heavy precipitations that quickly stop saltation by wetting the soil. In order to protect the optical counters and microbalances, the size distribution and mass concentration measurements were stopped immediately at the falling of the first raindrops.

In this study only the most significant events among those sampled on the field are retained. Based on the observation that during the strongest saltation events the number of impacts counted by either the Saltiphone or the Sensit reached several thousands per minute we decided to discard arbitrarily those corresponding to a number of impacts $<100$. This first numerical criterion also allows time location of the beginning and end of the main dust emission periods. A second criterion related to the event's duration and inherent to the gradient method used for computing the vertical particle flux was also used. As already mentioned above, application of Eq. (1) to derive dynamical parameters $\left(u^{*}, Z_{0}, R i\right.$, and $L$ ) from the wind profile measurements is possible only for time periods longer than $15 \mathrm{~min}$. Therefore, the lower limit of the duration was arbitrarily fixed at $30 \mathrm{~min}$ for enough data to be associated with an erosive period and it to be retained in this study. Finally, during the 2 SOPs 10 events, 5 of the monsoon type and 5 of the convective type were found to meet simultaneously the intensity and duration criteria but among them only 3 (ME1, ME4, and CE4) were able to pass the drastic quality insurance procedure applied to the data set. Table 1 presents some of their characteristics. Note that for these events the equivalent mass density obtained by comparison of the OPS and TEOM measurements is $2.38 \pm 0.24 \mathrm{~g} / \mathrm{cm}^{3}$, which is slightly lower than the density of pure quartz (2.65) generally adopted for dust particles in modelling studies. This difference can be explained at least 


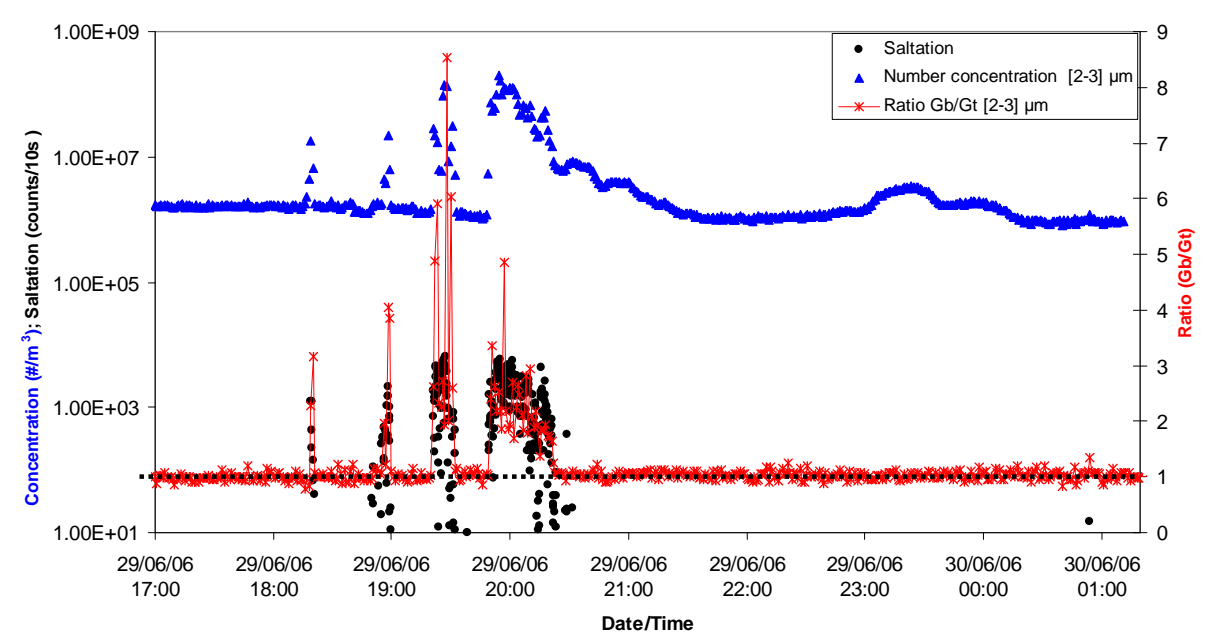

Fig. 4. Dust concentration (in particles $/ \mathrm{m}^{3}$ ) measured in the $2-3 \mu \mathrm{m}$ size class by the particle counter connected to the highest of the 2 sampling heads. The ratio of the concentrations measured at the two heights (red line) is larger than 1 only when sand movement is detected by the saltation detector (black dots).

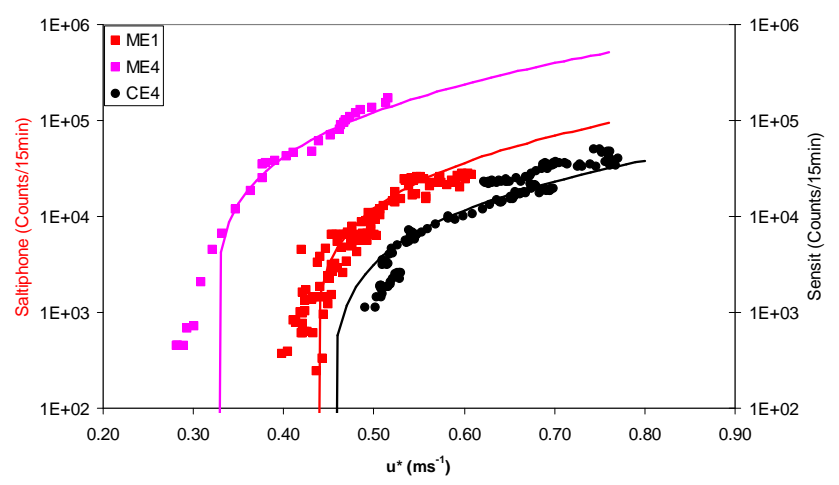

Fig. 5. Intensity of the saltation (in counts cumulated over $15 \mathrm{~min}$ ) detected by the Saltiphone during ME1 and ME4, and by the Sensit during CE4.. Note that because they were not cross-calibrated the counts given by the two instruments cannot be compared numerically. The best fit of White's (1986) equation to the measurements is reproduced in each case.

in part by the complex aggregated structure of supra micronic dust particles that is generally observed under scanning or transmission electron microscopes (e.g. Chou et al., 2008). Figure 3 provides an illustration of the good agreement that was obtained between the TEOM and OPC measurements. It corresponds to the data collected at the low level of the sampling system during ME1.

\subsection{Characteristics of the emission flux}

\subsubsection{Preliminary remark: impact of saltation on the SBL concentration in fine dust particle}

During saltation events, the particle concentration measured at both levels by either the TEOM or the OPS increase sys- tematically and often dramatically, but such increases also occur outside saltation periods. From this point of view, the case of 29 June 2006, during which ME4 occurred, is particularly illustrative. Indeed, it can be seen on Fig. 4 that concentrations measured at both levels by the OPS can increase simultaneously with and without local erosion occurring but it is only when saltation is detected by the Saltiphone that the ratio of low to high level concentrations becomes larger than 1. In other words, saltation must take place for a vertical ascending (emission) flux of fine particles to be observed. This is consistent with the theory of the sandblasting process stating that the emission of FD particles from a soil is a consequence of the movement of sand sized particles at its surface (Gillette., 1977; Shao., 1993; Alfaro and Gomes., 2001; Gomes et al., 2003). The simultaneous temporal fluctuations of concentrations at the two levels outside saltation periods (e.g. between 23:00 and 24:00 on Fig. 4) can be explained by dust advection, i.e. transport towards the measurement site of particles produced by saltation and sandblasting occurring upwind. This emphasizes that concentration measurements performed at a single level cannot be used alone for tracing local emissions.

Examination of the counts detected by the Saltiphone or the Sensit during the three studied events reveals (Fig. 5) that the threshold of saltation was significantly lower during ME4 $\left(u^{*}{ }_{t} \sim 0.30 \mathrm{~m} / \mathrm{s}\right)$ than during the other two events for which $u^{*}{ }_{t}$ is around $0.40 \mathrm{~m} / \mathrm{s}$. This discrepancy could potentially be a consequence of the difference in wind direction during ME4 on the one side and CE4 and ME1 on the other side (see Table 1). Indeed, Rajot et al. (2003) who performed measurements on a field in the same Sahelian area showed that the roughness of a natural surface seen by an air flow can depend on its direction. This is a result of the anisotropy of the crop residue cover and more generally of the large spatial 


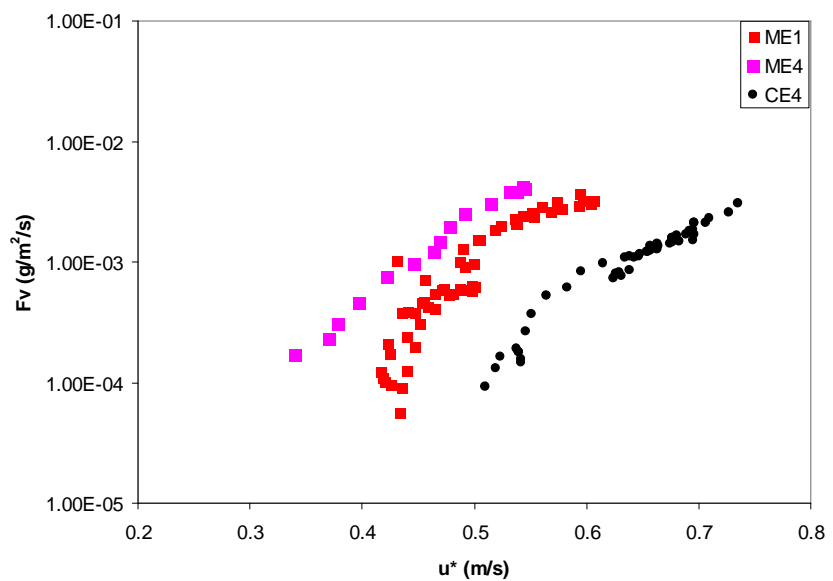

Fig. 6. Dust emission fluxes determined for the 3 erosion events by applying the gradient method whith the mass concentrations measured at two different levels in the SBL.

variability of the microtopography, and in turn has an influence on the value of the saltation threshold. Comparison of the average values of $Z_{0}$ obtained for the periods of the 3 erosion events (see Table 1 ) and showing that $Z_{0}$ is lower by an order of magnitude during ME4 than during CE4 and ME1 indicates that this dependence of $Z_{0}$ to wind direction is also observed in the current experiments.

Also noteworthy is the fact that for the 3 events the number of counts detected by the saltation detectors can be fitted almost perfectly by an equivalent of White's (1986) equation providing the number of impacts per time unit instead of the real saltation intensity for which it was originally designed (Fig. 5). This shows that White's parameterization of the movement of sand grains at the soil's surface is adapted to the description of saltation as observed in Banizoumbou. The fitting procedure also yields an estimate of the values of $u^{*}{ }_{t}$ given above but as detailed in the methodology section it does not allow comparison of the intensity of saltation between ME1 and ME4 on the one side and CE4 on the other side because the Saltiphone and the Sensit were not calibrated (Fig. 5).

\subsubsection{Magnitude of the vertical mass flux}

The vertical mass fluxes derived from the TEOM measurements and Eq. (2a) for the 3 events increase rapidly with $u^{*}$ (Fig. 6). Our results showing that the mass of fine dust released each second by a square meter of the source varies between 100 and several thousands $\mu \mathrm{g}$ compare well to those of Rajot et al. (2003) who had already determined the intensity of the dust emission mass flux over an agricultural field in the same area. These authors were using the same gradient method but the mass concentrations at the high and low levels were determined more classically by analyzing the content of dust samples collected on filters. These results compared

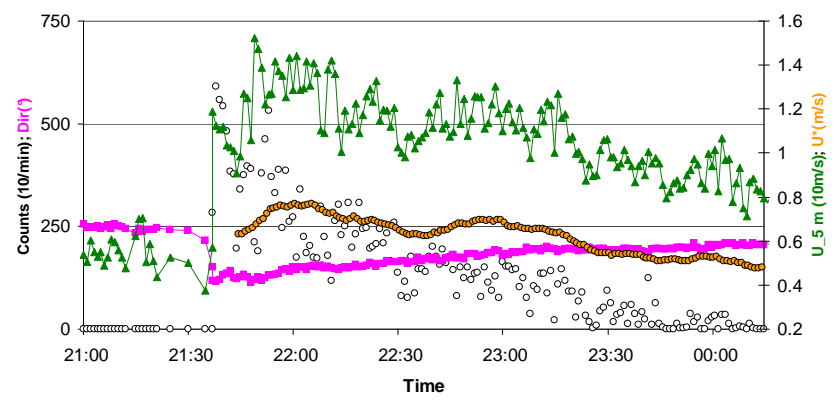

Fig. 7. Wind speed and direction recorded during the convective event (CE4) that occurred in the night of 22 June 2007. The intensity of saltation monitored by the Sensit and the wind friction velocity computed over periods of $15^{\prime}\left(u^{*}\right)$ are also reported.

also very well with all the field measurements available in the literature (Gillette, 1977; Nickling and Gillies, 1989; Alfaro et al., 2004). We consider this similarity of results as a direct validation of the TEOM-based measurements and as an indirect validation of the Grimm-based results that are consistent with the TEOM ones. In addition, the differences of emission intensity observed between the 3 events at similar wind friction velocities are consistent with the previous observations by Rajot et al. (2003) showing that changes in wind direction had an impact on the apparent soil roughness. This point will be discussed more in detail below.

\subsubsection{Size-resolved vertical flux}

\section{Detailed analysis of CE4}

Of all the convective events monitored during the two AMMA field measurement campaigns, CE4 is the longest (Table 1). Its exceptionally long duration ( $2 \mathrm{~h} 44 \mathrm{~min}$ ) can be explained 1) by an unusually large spatial extent as is apparent on the corresponding METEOSAT image (data not shown) and 2) by the fact that erosion was able to last for a longer time than usual because the convective system responsible for dust emission was not followed by rain shortly after reaching the experimental site as is common.

The event started sharply at $21 \mathrm{~h} 37 \mathrm{mn}$ with the arrival of the convective system (Fig. 7). In less than $1 \mathrm{~min}$ the wind turned from the southwest direction $\left(250^{\circ}\right)$ typical of Monsoon regimes to the east. At the same time wind speed measured at $5 \mathrm{~m}$ above ground level increased from 7.7 to $11.9 \mathrm{~m} / \mathrm{s}$ initiating immediately the saltation process. Close to its peak, which was reached approximately $15 \mathrm{~min}$ later the event was particularly intense. Indeed, the $1 \mathrm{~min}$ average of the wind speed reached a maximum value of $15.2 \mathrm{~m} / \mathrm{s}$ and the corresponding $15^{\prime}$ ' sliding average of $u^{*}$ was $0.77 \mathrm{~m} / \mathrm{s}$ (Fig. 7).

For studying the impact of $u^{*}$ on the magnitude and size distribution of the dust emission flux, the latter has been computed according to Eq. (2b) in every size class of the OPS. 
Table 1. Main characteristics of the 3 erosion events monitored at the Banizoumbou (Niger) supersite during the 2006 and 2007 special observation periods of AMMA and retained for this study. Two of them (ME1 and ME4) were events of the Monsoon type and one (CE4) was of the convective type.

\begin{tabular}{lcccccc}
\hline Event & Start & End & Duration & Wind direction $\left({ }^{\circ}\right)$ & $u^{*}(\mathrm{~m} / \mathrm{s})$ & $Z_{0}(\mathrm{~mm})$ \\
\hline ME1 & $06 / 06 / 23$ 01 h 34 min & $06 / 06 / 23$ 03 h 43 min & 2h 09 min & {$[150-196]$} & {$[0.40-0.60]$} & $1.70( \pm 30 \%)$ \\
ME4 & $06 / 06 / 29$ 19h 49 min & $06 / 06 / 29$ 20 h 28 min & 39 min & {$[220-240]$} & {$[0.30-0.50]$} & $0.23( \pm 24 \%)$ \\
CE4 & $07 / 06 / 22$ 21 h 37 min & $07 / 06 / 23$ 00 h 11 min & 2h 44 min & {$[112-210]$} & {$[0.40-0.80]$} & $3.70( \pm 10 \%)$ \\
\hline
\end{tabular}

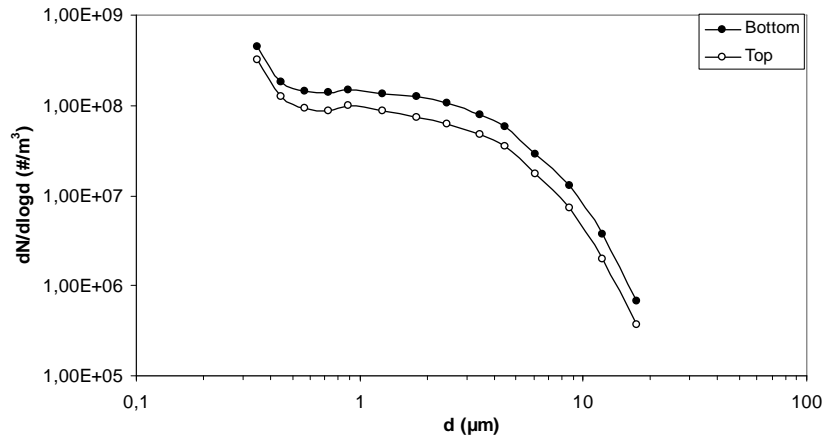

Fig. 8. Averages of the size-resolved particle concentration $(d N / d \log d)$ measured at the low and high sampling levels during ME1. Note that the concentration at the lowest level is larger than the one at the highest level, which characterizes an upward direct flux and is typical of an erosion event.

Practically, the computation was performed for each minute with the values of the sliding averages of concentrations and $u^{*}$ corresponding to the $15^{\prime}$ period centered on it. Figure 8 illustrates the shape of the size-resolved concentrations measured by the OPCs at the bottom and top levels and from which the upward emission flux was derived.

For CE4, $u^{*}$ values varied between $0.45 \mathrm{~m} / \mathrm{s}$ and $0.80 \mathrm{~m} / \mathrm{s}$, which is to say up to values well above the threshold of saltation. This emphasizes again the energetic conditions of the convective event for which very high $u^{*}$ values were reached. The results of the flux calculations show that at all friction speeds above $0.5 \mathrm{~m} / \mathrm{s}$ an emission flux could be measured in every size class of the OPS. This proves that the size spectrum of emitted particles was at least as wide as the measuring possibilities of the OPS and also underlines one of the limits of our measurements that were not able to size particles smaller than $0.3 \mu \mathrm{m}$. At speeds below $0.5 \mathrm{~m} / \mathrm{s}$, a flux was computed in the size classes under $8-10 \mu \mathrm{m}$ but the use of the diluting system limited too dramatically the number of the coarsest $(>15 \mu \mathrm{m})$ particles for allowing an accurate determination of the corresponding emission flux (data not shown). At any given wind speed, this flux varies by more than 3 orders of magnitude over the measurement range of sizes. An illustration of this variation is given by Fig. 9 on which the flux averaged over the whole duration of CE4 is re-

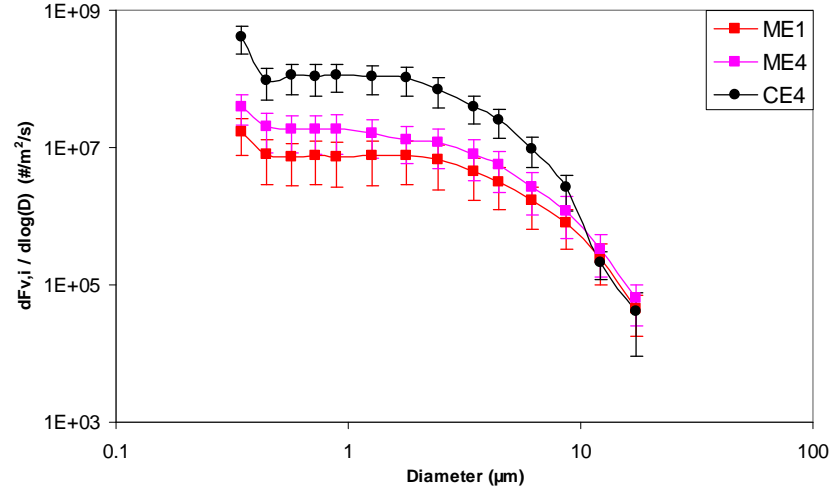

Fig. 9. Average size-resolved fluxes measured during the convective (CE4) and Monsoon (ME1 and ME4) events. The length of the error bars corresponds to the standard deviation.

ported. From slightly above $10^{5}$ particles $/ \mathrm{m}^{2} / \mathrm{s}$ for particles in the $10-15 \mu \mathrm{m}$ class it goes up to more than $10^{8} \mathrm{particles} / \mathrm{m}^{2} / \mathrm{s}$ in the finest class of the OPS $(0.3-0.4 \mu \mathrm{m})$. At all speeds, the characteristics of the size distribution are found to be similar: 1) the largest flux is obtained in the $0.3-0.4 \mu \mathrm{m}$ class, which could possibly confirm the existence of a very fine mode (VFP) of submicron particles (Gomes et al. 1990) located mostly below the measuring range of the OPS, 2) the flux of fine particles (FP) having sizes between 0.4 and $2.0 \mu \mathrm{m}$ is almost constant, and 3) the flux of particles coarser than $2 \mu \mathrm{m}$ (CP) decreases with size. Note that these number size distributions measured on the field in erosion conditions and in which an important fraction of the emission flux is located in the submicron range are also in good qualitative agreement with the wind tunnel measurements of Alfaro et al. (1997) and the model derived from them (Alfaro and Gomes, 2001).

In order to document more precisely the increase with wind speed of the emission flux, the values of $F_{v, i}$ determined each minute with the $15^{\prime}$ averages of concentrations and $u^{*}$ can been plotted as a function of $u^{*}$ for three size classes $(0.3-0.4,0.5-0.65$, and $8.0-10.0 \mu \mathrm{m})$ representative of VFP, FP, and CP, respectively. Results (Fig. 10) show that $F_{v, i}$ increases by more than 2 orders of magnitude over the $0.50-0.75 \mathrm{~m} / \mathrm{s}$ range of $u^{*}$, and this for the 3 types of 


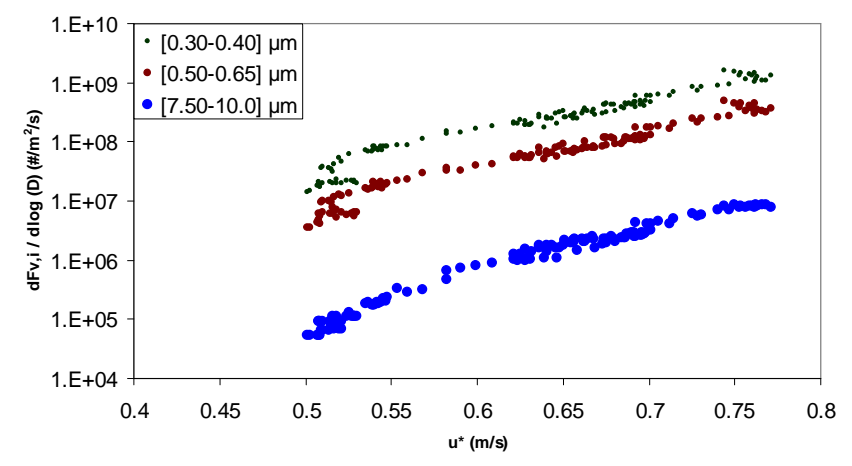

Fig. 10. Influence of $u^{*}$ on the fluxes measured in 3 size-classes representative of the particles emitted by wind erosion during the CE4 convective event (see text for details).

particles. The fact that the 3 plots are almost perfectly parallel suggests that in spite of the relatively important variations in magnitude of the emission flux, its size distribution does not seem to vary significantly during $\mathrm{CE} 4$, and remains similar to the one of the average flux represented previously on Fig. 7.

\section{Comparison with other erosion events}

The other two events (ME1 and ME4) retained for this study are of the monsoon type and their ranges of $u^{*}$ are $0.40-0.60$ and $0.30-0.50 \mathrm{~m} / \mathrm{s}$, respectively. These values significantly lower than those observed during the convective event indicate that the two monsoon events were less energetic than the convective one. This is especially true of ME4 for which measurements are available at particularly small $u^{*}$ because its saltation threshold was found to be much lower than the ones of CE4 and ME4 (see above).

The size-resolved fluxes averaged over the durations of ME1 and ME4 can be compared to the one of CE4 directly in terms of numbers (Fig. 9) or after having been converted into mass (Fig. 11) using a sphericity assumption and the particles density $\left(2.4 \mathrm{~g} / \mathrm{cm}^{3}\right)$ derived from the comparison of the TEOM and OPC measurements.

As was already the case of CE4, the magnitude of the emission flux in each size class follows the variations of $u^{*}$ but the size-distribution seems to be somewhat invariant during ME1 and ME4. Though the range of $u^{*}$ variation reaches slightly larger values during ME1 than during ME4, the intensity of FD emission measured during the first event is lower than during the second one. The explanation for this difference could be the lower threshold of saltation during ME4 due to lower roughness length. Indeed, for any value of $u^{*}$ larger than $0.40 \mathrm{~m} / \mathrm{s}$, which is to say above the thresholds of saltation of the two events, the intensity of saltation is larger in the case of ME4 (see Fig. 5). In turn, this more intense saltation promotes sandblasting and leads to a larger vertical flux of FD. This also implies that direct comparison

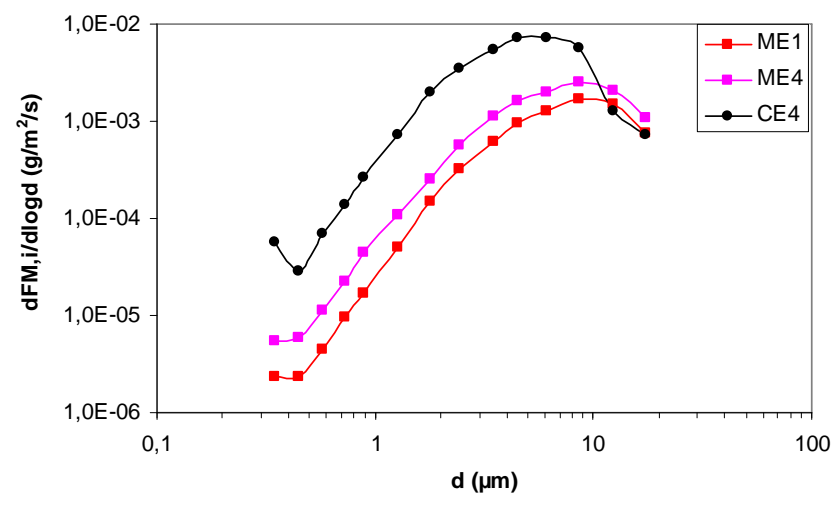

Fig. 11. Average emission fluxes for the 3 events of this study. These mass fluxes have been computed from the number fluxes of fig.9. Note the shift of the mass distribution towards smaller sizes in the case of the energetic event (CE4).

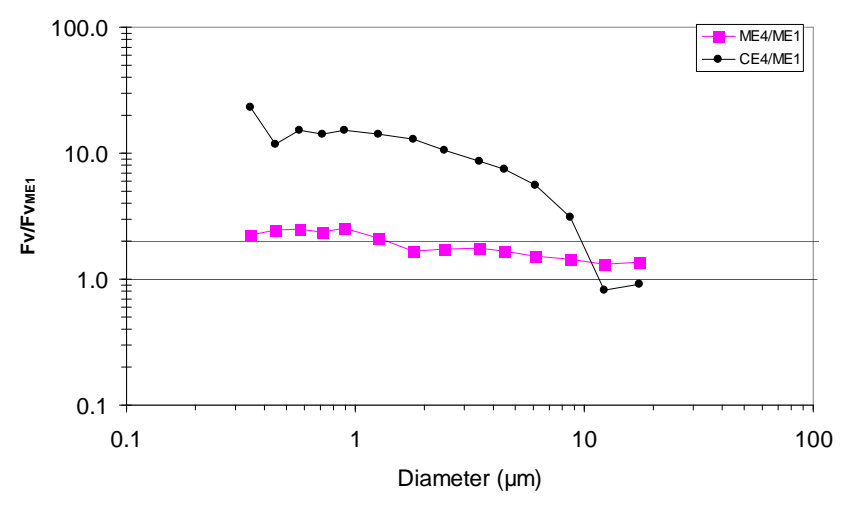

Fig. 12. Comparison of the size-resolved fluxes measured during one monsoon (ME4) and one convective (CE4) events with the one measured during the monsoon event chosen as a reference case (ME1).

of fluxes produced at a given value of $u^{*}$ is possible only if it has been checked previously that the $Z_{0}$ were similar.

The average size-resolved fluxes of fine particles observed during CE4 and during ME4 can be compared numerically (Fig. 12) to the average flux of ME1 chosen as a reference case because it corresponds to the lower saltation intensity. The ratio of the fluxes measured during ME4 to those measured during ME1 decreases only slightly with particle size and remains basically close to $2(1.9 \pm 0.4)$. This shows that though the average particle flux released during ME4 is approximately twice the one of ME1 in all the size-classes of the OPS, the emitted flux is only slightly richer in very fine particles during the first event. As detailed above, this similarity of size distributions during the two events must be related to the closeness of their ranges of $u^{*}$ variations.

The comparison of CE4 with ME1 yields a quite different result. Indeed, fluxes measured during the two events are not in the least proportional. Although fluxes are similar in 
the size-classes larger than $10 \mu \mathrm{m}$ (their ratio is close to 1 , which indicates that emission of these particles is relatively insensitive to wind speed),, the proportion of fine particles in the emission flux increases rapidly with decreasing particle size during CE4. This shows that the emission flux is much richer in fine particles during CE4 than during either one of the two monsoon events studied in this work. This must be related to the much larger values of $u^{*}$ reached during this energetic event.

There is an apparent contradiction between the fact that the high energy event releases much finer dust than the two moderate ones but that internal variations of $u *$ inside a given event do not seem to affect this size-distribution. This could be due to the difference of time scales between the computation of $u^{*}$ on the one side and of the erosion processes on the other side. As already detailed by Stout (1998), saltation and, as a matter of consequence, sandblasting respond almost instantaneously to fast fluctuations in wind intensity provided this one becomes larger than the saltation threshold. In addition, the increase of the saltation flux above threshold is much faster than predicted by linear functions. In these conditions, it can be understood that a meteorological parameter $\left(u^{*}\right)$ derived from a simple arithmetic average performed over a duration much longer than the typical response time of Aeolian microphysical processes might not be the best choice for predicting their numerical consequences.

\section{Concluding remarks}

In this work three major dust events of the 2006 and 2007 AMMA special observations periods have been analyzed in detail for studying the potential impact of wind speed on the initial size distribution of the emission flux. Two of these events (ME1 and ME4) were of the Monsoon type, which is to say due to a temporal increase in the strength of the south-western wind that prevails in the Sahel at the onset of the rainy season, and the other one (CE4) was due to a mesoscale convective system and therefore classified in the so-called convective type of erosive events. The first result of this study is that no vertical upward dust flux was observed outside saltation periods, which is in good agreement with the sandblasting theory stating that the shocks of sand-sized grains are at the origin of the release of fine dust particles. The second type of results related to the characterization of the dust flux size-distribution is completely original. Indeed, our measurements show that if this size distribution is fairly constant during an individual erosion event, and this in spite of relatively important temporal variations of $u^{*}$, large differences are observed between the highly energetic convective events and the more moderate Monsoon ones. More precisely, though wind conditions during CE4 were much more energetic than during ME1 or ME4, the dust emission flux of particles larger than $10 \mu \mathrm{m}$ was in the same order of magnitude during the 3 events. Conversely, a significant enrich- ment exceeding a factor 10 for particles smaller than $2 \mu \mathrm{m}$ and 20 in the case of particles smaller than $0.4 \mu \mathrm{m}$ was observed. This is the first direct observation made in a dust source area indicating that the initial size distribution of dust released by wind erosion depends on the aerodynamic conditions prevailing during its generation. This is in good qualitative agreement with the results of experiments performed previously in a laboratory wind tunnel and showing that the larger the kinetic energy of the saltating soil aggregates, the larger the proportion of very fine particles in the flux of particles released by the sandblasting process.

A more quantitative comparison of the AMMA field results with the predictions of the dust production model derived from the aforementioned wind tunnel experiments is planned to validate, or if necessary improve, the model.

Acknowledgements. Acknowledgment. Based on a French initiative, AMMA was built by an international scientific group and is currently funded by a large number of agencies, especially from France, UK, US and Africa. It has been the beneficiary of a major financial contribution from the European Community's Sixth Framework Research.

The authors are also grateful to all the persons from the IRD and LISA who have made the experiment possible first by setting up the experimental site and subsequently by servicing it in difficult conditions during the two intensive observation periods of 2006 and 2007. They also thank the "Institut National des Sciences de l'Univers" (INSU/CNRS) for his support.

Edited by: J. Williams

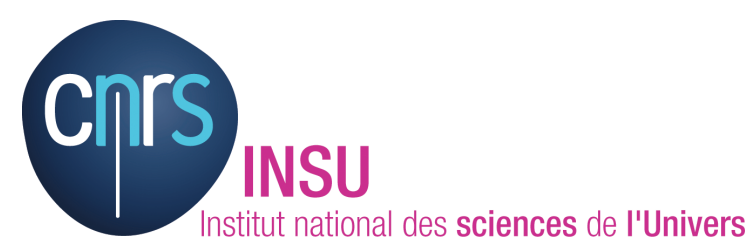

The publication of this article is financed by CNRS-INSU.

\section{References}

Alfaro, S. C. and Gomes, L.: Improving the large-scale modelling of the saltation flux of soil-particles in presence of non erodible elements, J. Geophys.Res., 100, 16357-16366, 1995.

Alfaro, S. C., Gaudichet, A., Gomes, L., and Maillé, M.: Modelling the size distribution of a soil aerosol produced by sandblasting, J. Geophys. Res., 102, 11239-11249, 1997.

Alfaro, S. C., Gaudichet, A., Gomes, L., and Maillé, M.: Mineral aerosol production by wind erosion: aerosol particle sizes and binding energies, Geophys. Res. Lett., 25(7), 991-994, 1998.

Alfaro, S. C. and Gomes, L.: Modelling mineral aerosol production by wind erosion: Emission intensities and aerosol distributions in source areas, J. Geophys. Res., 106, 18075-18084, 2001.

Alfaro, S. C., Rajot, J. L., and Nickling, W.: Estimation of PM20 emissions by wind erosion: Main sources of uncertainties, Geomorphology, 59, 63-74, 2004. 
Belnap, J.: Biological soil crusts and wind erosion, edited by: Belnap, J. and Lange, O. L., in: Biological soil crusts: structure, function, and management, Ecological studies 150, SpringerVerlag, New York, 340-347, 2003.

Bielders, C. L., Michels, K. and Rajot, J. L.: On-farm Evaluation of ridging and residue Management Practices to reduce wind Erosion in Niger, Soil Sci. Soc. Am. J., 64, 1776-1785, 2000.

Bielders, C. L., Rajot, J. L., and Amadou, M.: Tranport of soil and nutrients by wind in bush fallow land and traditionally managed cultivated fields in the Sahel, Geoderma, 109, 19-39, 2002.

Bielders, C. L., Rajot, J. L., and Michels, K.: L'érosion éolienne dans le Sahel Nigérien : influence des pratiques culturales actuelles et méthodes de lutte, Sécheresse, 15(1), 19-32, 2004.

Chatenet, B., Marticorena, B., Gomes, L., and Bergametti, G.: Assessing the actual grain-size distributions of desert soils erodible by wind, Sedimentology, 43, 901-911, 1996.

Chou, C., Formenti, P., Maille, M., Ausset, P., Helas, G., Harrison, M., and Osborne, S.: Size distribution, shape, and composition of mineral dust aerosols collected during the African Monsoon Multidisciplinary Analysis Special Observation Period 0: Dust and Biomass-Burning Experiment field campaign in Niger, January 2006, J. Geophys. Res., 113, D00C10, doi:10.1029/2008JD009897, 2008.

D'almeida, G. and Schütz, L.: Number, Mass and Volume Distribution of Mineral Aerosol and Soils of the Sahara, American Meteorology Society, 223-243, 1983.

Fécan, F., Marticorena, B., and Bergametti, G.: Parametrization of the increase of the aeolian erosion threshold wind friction velocity due to soil moisture for arid and semi-arid areas, Ann. Geophys., 17, 149-157, 1999,

http://www.ann-geophys.net/17/149/1999/.

Frangi, J. P. and Richard, D. C.: The WELSONS experiment: overview and presentation of first results on the surface atmospheric boundary-layer in semiarid Spain, Ann. Geophys., 18, 365-384, 2000,

http://www.ann-geophys.net/18/365/2000/.

Gillette, D., Blifford, I. H., and Fenster, C. R.: Measurements of aerosol size distributions and fluxes of aerosols on land subject to wind erosion, J. Appl. Meteorol., 11, 977-987, 1972.

Gillette, D. A.: Fine particulate emissions due to wind erosion, Trans. Am. Soc. Agric. Eng., 20, 5, 890-897, 1977.

Gomes, L., Bergametti, G. Coudé-Gaussen, G., and Rognon, P.: Submicron Desert dusts: A sandblasting process, J. Geophys. Res., 95, 13927-13935, 1990.

Gomes, L., Rajot, J. L., Alfaro, S. C., and Gaudichet, A.: Validation of a dust production model from measurements performed in Spain and Niger, Catena, 52(3-4), 257-271, 2003.

Greeley, R. and Iversen, J.: Wind as a Geological Process on Earth, Mars, Venus and Titan. Cambridge Planetary Sciences Series, Cambridge Univ. Press., Cambridge. 333 pp., 1985.

Houser, C. A. and Nickling, W. G.: The emission and vertical flux of particulate matter $<10 \mathrm{Am}$ from a disturbed clay-crusted surface, Sedimentology, 48, 255-267, 2001.

Jaenicke, R., Junge, C. and Kanter, H. J.: Messungen der Aerosolgrößenverteilung über dem Atlantik, Meteor. Forsc. Ergeb., B7, 1-54, 1971.

Jickells, T. D., An, Z. S., Andersen, K. K., Baker, A. R., Bergametti, G., Brooks, N., Cao, J. J., and Boyd, P. W.: Global Iron Connections Between Desert Dust, Ocean Biogeochemistry and
Climate, Science, 308, 67-71, 2005.

Levin, Z., Ganor, E., and Gladstein, V.: The effect of desert particles coated with sulfate on rain formation in the Eastern Mediterranean, American Meteorological Society, 35, 1511-1523, 1995.

Marticorena, B. and Bergametti, G.: Modeling the atmospheric dust cycle: 1 . Design of a soil-derived dust emission scheme, J. Geophys. Res., 100, 16415-16430, 1995.

Marticorena, B., Kardous, M., Bergametti, G., Callot, Y., Chazette, P., Khatteli, H., Le Hégarat-Mascle, S., Maillé, M., Rajot, J. L., Vidal-Madjar, D., and Zribi, M.: Aeolian geometric and aerodynamic surface roughness in arid and semi-arid areas and their relation with radar backscatter coefficient, J. Geophys. Res., 111, F03017, doi:10.1029/2006FJ000462, 2006.

Monin, A. S. and Obukhov, A. M.: Basic laws of turbulent mixing in the atmosphere near the ground, Tr.Akad.Nauk., SSR Geophiz.Inst, 24(151), 1963-1987, 1954.

Nickling, W. G. and Gillies, J. A.: Emission of fine-grained particulates from desert soils, in: Paleoclimatology and Paleometeorology: Modern and Past Patterns of Global Atmospheric Transport, edited by: Leinen, M. and Sarntheim, M., Kluwer Academic Publishing, Dordrecht, 133-165, 1989.

Peters, T. M., Ott, D., and O'Shaughnessy, P. T.: Comparaison of the Grimm 1.0108 and 1.0109 Portable Aerosol Spectometer to the TSI 3321 Aerodynamic Particle Sizer for Dry Particles, Ann. Occup. Hyg., 50(8), 843-850, 2006.

Rajot, J. L., Sabre, M., and Gomes, L.: Measurement of vertical fluxes of soil-derived dust during wind erosion events in a Sahelian region (Niger, Proceedings of International Symposium Wind erosion in West Africa: The problem and its control, Hohenheim, 5-7 Décembre 1994, 1995.

Rajot, J. L.: Wind blown sediment mass budget of Sahelian village land units in Niger, Bull. Soc. Géol. France, 172(5), 523-531, 2001.

Rajot, J. L., Alfaro, S. C., Gomes, L., and Gaudichet, A.: Influence of sandy soil crusting on horizontal and vertical wind erosion fluxes, Catena, 53(1), 1-16, 2003.

Rajot, J. L., Formenti, P., Alfaro, S., Desboeufs, K., Chevaillier, S., Chatenet, B., Gaudichet, A., Journet, E., Marticorena, B., Triquet, S., Maman, A., Mouget, N., and Zakou, A.: AMMA dust experiment: An overview of measurements performed during the dry season special observation period (SOP0) at the Banizoumbou (Niger) supersite, J. Geophys. Res., 113, D00C14, doi:10.1029/2008JD009906, 2008.

Shao, Y., Raupach, M. R., and Findlater, P. A.: Effect of saltation bombardment on the entrainment of dust by wind, J. Geophys. Res., 98, 12719-12726, 1993.

Spaan, W. P. and van den Abeele, G. D.: Wind borne particle measurements with acoustic sensors, Soil Technol., 4, 51-63, 1991.

Stout, J. E.: Effect of averaging time on the apparent threshold for aeolian transport, J. Arid Environ., 39, 395-401, 1998.

Swap, R., Garstang, M., Greco, S., Talbot, R., and Gac, J. Y.: Sahara dust in Amazon basin, Tellus ser, B44, 133-149, 1992.

White, B. R.: Encyclopedia of Fluid Mechanics, pp 239-282, Gulf, Houston, Tex, 1986.

Wieringa, J.: Representative roughness parameters for homogeneous terrains, Boundary Layer Meteorol., 63, 323-363, 1993. 